Does Direct Democracy Hurt Immigrant Minorities? Evidence from Naturalization Decisions in Switzerland

\author{
Journal Article \\ Author(s): \\ Hainmueller, Jens; Hangartner, Dominik \\ Publication date: \\ 2019-07 \\ Permanent link: \\ https://doi.org/10.3929/ethz-b-000357765
}

Rights / license:

Creative Commons Attribution-NonCommercial 4.0 International

Originally published in:

American Journal of Political Science 63(3), https://doi.org/10.1111/ajps.12433 


\title{
Does Direct Democracy Hurt Immigrant Minorities? Evidence from Naturalization Decisions in Switzerland 0
}

\author{
Jens Hainmueller Stanford University \\ Dominik Hangartner ETH Zurich \& London School of Economics
}

\begin{abstract}
Do minorities fare worse under direct democracy than under representative democracy? We provide new evidence by studying naturalization requests of immigrants in Switzerland that were typically decided with referendums in each municipality. Using panel data from about 1,400 municipalities for the 1991-2009 period, we exploit Federal Court rulings that forced municipalities to transfer the decisions to their elected municipality councils. We find that naturalization rates surged by about $60 \%$ once politicians rather than citizens began deciding on naturalization applications. Whereas voters in referendums face no cost of arbitrarily rejecting qualified applicants based on discriminatory preferences, politicians in the council are constrained to formally justify rejections and may be held accountable by judicial review. Consistent with this mechanism, the increase in naturalization rates caused by switching from direct to representative democracy is much stronger for more marginalized immigrant groups and in areas where voters are more xenophobic or where judicial review is more salient.
\end{abstract}

Replication Materials: The materials required to verify the computational reproducibility of the procedures and analyses in this article are available on the American Journal of Political Science Dataverse within the Harvard Dataverse Network, at: https://doi.org/10.7910/DVN/T8OYHT.

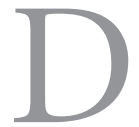

oes direct democracy hurt minorities? This fundamental question has divided scholars from the birth of Athenian democracy to currentday controversies over referendums in American states, Switzerland, and many other countries. Although many praise the virtues of direct democracy as the most democratic means of enacting legislation, others have long cautioned that do-it-yourself government by citizens threatens the interests of minorities (Madison 1961). But despite considerable scholarly work on the topic, our understanding of how different forms of democratic government affect minority interests continues to be limited. Some studies of direct democracy provide evidence for a systematic anti-minority bias (Gamble 1997; Haider-Markel, Querze, and Lindaman 2007; Hajnal 2009; Schildkraut 2001), whereas others suggest that direct democratic decisions do not systematically suppress minorities and may even enable them to protect their interests (Cronin 1989; Donovan and Bowler 1998; Frey and Goette 1998; Hajnal, Gerber, and Louch 2002; Zimmerman and Francis 1986). And while critics of direct democracy are quick to cite popular votes that have infringed upon the rights of minorities, supporters argue that such decisions are often simply window dressing because legislatures would have

Jens Hainmueller is Professor, Department of Political Science, Immigration Policy Lab, and Graduate School of Business, Stanford University, 616 Serra Street, Stanford, CA 94305 (jhain@stanford.edu).Dominik Hangartner is Associate Professor, Public Policy Group and Immigration Policy Lab, ETH Zurich, Leonhardshalde 21, 8090 Zurich, Switzerland; and Department of Government, London School of Economics and Political Science, Houghton Street, London WC2A 2AE, United Kingdom (d.hangartner@lse.ac.uk).

We thank the seminar participants at the Institute for Advanced Studies Lucca, Massachusetts Institute of Technology, University of Bern, University of Essex, Stanford University, University of California San Diego, University of California Berkeley, Washington University in St. Louis, and the University of Geneva for their helpful comments. We thank Matthias Christen, Roman Kuster, Fabian Morgenthaler, Emilia Pasquier, Giuseppe Pietrantuono, Rocco Pietrantuono, Livio Raccuia, Mirjam Rütsch, Laura Schmid, and Tess Wise for excellent research assistance. We would especially like to thank the head secretaries of the municipalities for participating in our survey and interviews, Marc Helbling and Marco Steenbergen for their valuable support, Eva Andonie for expert legal counsel, and Rafaela Dancygier, David Laitin, Duncan Lawrence, Didier Ruedin, Lucas Stanczyk, Ingemar Stenmark, Hanspeter Kriesi, and Catherine de Vries for providing detailed comments. Funding for this research was generously provided by Swiss National Science Foundation grant no. 100017_132004.

American Journal of Political Science, Vol. 63, No. 3, July 2019, Pp. 530-547

(C) 2019 The Authors. American Journal of Political Science published by Wiley Periodicals, Inc. on behalf of Society for American Journal of Political Science

DOI: $10.1111 /$ ajps.12433

This is an open access article under the terms of the Creative Commons Attribution-NonCommercial License, which permits use, distribution and reproduction in any medium, provided the original work is properly cited and is not used for commercial purposes. 
passed similar measures even in the absence of the direct democratic vote. As Matsusaka $(2005,201)$ concludes in a recent review,

Legislatures have harmed minorities, tooalmost all Jim Crow laws throughout the South were brought about by legislatures - and elected representatives, not direct democracy, interned Japanese-American citizens during World War II. There is no convincing evidence-anecdotal or statistical-that minority rights are undermined by direct democracy with a greater regularity than by legislatures.

The reason for the absence of "convincing evidence" on the effects of direct democracy on minority outcomes is that identifying the causal effect of direct democracy is a challenging empirical enterprise. Most existing studies simply count how often minority positions lose in popular votes; however, they lack a control group to infer whether minority outcomes would have been better if the same decisions had been taken under representative democracy. Only a few studies go further and use cross-sectional data to compare minority outcomes in jurisdictions with and without direct democratic provisions. However, this raises common concerns about endogeneity and omitted variable bias because jurisdictions with and without direct democracy differ on a plethora of unmeasured confounding characteristics—such as voter preferences, historical legacies, or political culture-that independently affect minority outcomes.

Common strategies to deal with omitted variable bias, such as natural experiments and fixed effects estimation with panel data, have not been applied to this topic because constitutional provisions about direct democracy rarely change over time. To our knowledge, thus far, no study has relied on natural experiments that exploit plausibly exogenous changes in direct democracy to identify its impact on minority outcomes. From a policy perspective, this lack of reliable knowledge regarding the impact of direct democracy on minority outcomes is troubling because direct democracy has become increasingly fashionable in recent decades. More than half of all American states and cities already provide for initiatives and referendums, and many European countries frequently use referendums for a wide range of policy decisions (Hug 2003).

In this study, we address this gap and advance a natural experiment that considers the causal effect of direct democracy on the naturalization rates of immigrant minorities in Switzerland. Naturalization rates are an important outcome because naturalization is the pathway through which immigrants obtain the right to vote, the right to permanently stay in the host country, and, as correlational studies suggest, access to better jobs and higher wages (e.g., OECD 2011). Quasi-experimental evidence also shows that naturalization propels the political and social integration of immigrants (Hainmueller, Hangartner, and Pietrantuono 2015, 2017).

In Switzerland, citizenship applications of immigrants are decided by the municipality in which the immigrant resides. Municipalities use two main types of regimes to vote on naturalization applications: direct democracy, in which citizens vote on the applications using referendums, and representative democracy, in which elected legislators vote on the applications in the municipality council. This configuration has generated a wealth of data that enable us to examine whether immigrant minorities fare better or worse if their naturalization requests are decided by the people or by legislatures. We collected an original annual panel data set that combines information about the local institutions and naturalization rates for a representative sample of about 1,400 municipalities for the 1991-2009 period. Our identification strategy exploits a series of rulings by the Swiss Federal Court in 2003-5 that forced most municipalities to change their decision-making process from direct to representative democracy. This rare instance of a large-scale, plausibly exogenous, institutional variation over time allows us to identify the effect of switching from direct to representative democracy in a design-based framework that exploits within-municipality variation, thereby ruling out time-invariant confounders.

We find that the sudden transition from direct to representative democracy sharply increased naturalization rates by about $60 \%$. This effect is robust to various specification checks, including time-varying covariates, linear and quadratic municipality-specific time trends to account for local trends in unobserved confounders, and various other specifications. Moreover, given that it takes 3-5 years of administrative processing time before a submitted application is put to the vote, applicants could not have anticipated the institutional change, and therefore the sharp increase in naturalization rates cannot be explained by sudden changes in the applicant pool. Essentially, lucky immigrants whose applications were to be decided in the municipal council stood a much better chance of being approved compared to unlucky applicants who were similarly qualified but had applied in the same municipality just a few months earlier such that their applications would still be voted on at the citizens' assembly. Consistent with this design-based identification strategy, placebo tests confirm that there are no differential trends in naturalization rates for each of the 5 years prior to the institutional switch but much higher naturalization rates 
for each of the 3 years following the switch from direct to representative democracy.

We also investigate several mechanisms that might explain why immigrants fare much better when politicians in legislatures rather than citizens in referendums decide on naturalization applications. Semi-structured interviews conducted with head secretaries of a random sample of the switching municipalities suggest that an important mechanism through which immigrants benefit is the heightened legal accountability that accompanies the transition of decision-making power from the people to the politicians. Voters in referendums are largely unconstrained to vote "sincerely" because they do not have to formally justify their decisions and face no reputational costs from arbitrarily rejecting qualified applicants based on discriminatory preferences against particular immigrant groups. In contrast, representative democracy requires that accountable politicians publicly report on the reasons for voting to reject an applicant, and these justifications are subject to judicial oversight by the courts if applicants appeal. These constraints increase the costs for politicians to arbitrarily reject applicants on the basis of discriminatory judgments, even if politicians are potentially just as prejudiced against particular immigrant groups as voters. Consistent with this legal accountability mechanism, which is to our knowledge novel in the literature on direct democracy, additional tests confirm that switching from direct to representative democracy is most beneficial for applicants who live in the most xenophobic municipalities or belong to more marginalized origin groups (e.g., former Yugoslavia or Turkey). Moreover, successful appeals against arbitrary rejections, which raise awareness about judicial oversight, result in higher naturalization rates only when politicians instead of voters decide on applications.

Overall, the results present perhaps the most direct evidence to date that, when faced with the same policy decision, direct democracy disadvantages minorities with greater regularity than legislatures. The outcomes for immigrant minorities in Switzerland are systematically more negative if their naturalization applications are decided by people rather than legislatures. In the Conclusion section, we elaborate on the theoretical and policy implications of our findings.

\section{Direct Democracy and Minorities}

A sizable literature has investigated the relationship between direct democracy and minority interests. Most studies have used what might be called a "countingup" approach and have examined how often minorities win or lose in direct democratic votes. This approach has yielded mixed results, with some studies supporting and others refuting the existence of a systematic anti-minority bias (Cronin 1989; Donovan and Bowler 1998; Frey and Goette 1998; Gamble 1997; HaiderMarkel, Querze, and Lindaman 2007; Hajnal, Gerber, and Louch 2002; Moore and Ravishankar 2012; Tolbert and Smith 2006; Vatter and Danaci 2010; Zimmerman and Francis 1986). While this counting-up approach is well suited to study the dynamics of popular votes, it does not provide knowledge about the effect of direct versus representative democracy on minority outcomes. The design lacks a control group to measure the missing counterfactual of how well the same minorities would have fared if the same decisions had been taken under representative democracy (Gerber and Hug 2001; Matsusaka 2005).

The important, and largely unanswered, question is whether representative democracy is systematically better at protecting minority rights than direct democracy. Only about a handful of studies have gone further and compared minority outcomes under different democratic regimes (Haider-Markel, Querze, and Lindaman 2007; Helbling and Kriesi 2004; Preuhs 2005; Schildkraut 2001; Vatter and Danaci 2010). However, since direct democratic institutions rarely change over time, these studies are limited to cross-sectional comparisons. It has been well rehearsed in the literature that cross-sectional study designs are insufficient to remove the selection bias that results from the endogeneity of political institutions (Acemoglu 2005; Olken 2010; Przeworski 2007). Direct democratic institutions, such as the initiative process in America or popular votes in Swiss municipalities, are not exogenously assigned, but result from endogenous and complex historical processes. Therefore, jurisdictions that established direct democracy differ in many ways from jurisdictions that did not, including important geographic, cultural, economic, and political differences that are correlated with minority outcomes. For example, in America the initiative is much less common in the South, and this geographic imbalance is correlated with different histories and policies regarding ethnic and racial minorities. Many of these confounding factors cannot be measured, and even if they could be measured, one quickly runs out of comparison cases when dealing with small samples of comparable jurisdictions. In this study, we address this issue by utilizing a natural experiment that enables us to exploit a rare instance of large-scale and plausibly exogenous over-time variation in direct democracy. 


\section{Naturalizations in Switzerland}

Switzerland employs a system of triple citizenship that delegates the responsibility for naturalization decisions to the municipal level (for details, see Hainmueller and Hangartner 2013). Immigrants who want to apply for Swiss citizenship have to complete a residency requirement of at least 12 years, after which they can submit their naturalization application to the municipality in which they reside. The municipality then forwards the application to the federal and cantonal authorities for various background checks, and if the outcome of this evaluation is positive, the municipality eventually invites the applicant for an interview to assess the applicant's language skills, integration status, and financial situation. Following this local assessment, the application is submitted to the local naturalization institution for a vote on the final decision. Usually between 3 and 5 years elapse from the submission of the first application form to the final vote. This lengthy processing period is an important part of our identification strategy because it rules out the possibility that applicants could have anticipated the change in the institution that was used to vote on their naturalization request.

Municipalities use different institutional arrangements to autonomously vote on naturalization applications. In the period under investigation (1991-2009), the institutional regimes can be roughly classified into three types:

Direct Democracy: Swiss residents decide on the pending naturalization requests by voting in a referendum on each applicant. Applicants who receive a majority of "yes" votes obtain a Swiss passport. In most municipalities, the referendums are held at the citizens' assemblies where citizens meet at regular intervals to decide on various municipal matters, and votes are commonly cast by hand raising. Prior to 2003, in a small number of municipalities, which we refer to as ballot box municipalities, citizens submitted their ballots for the referendums not at the citizens' assemblies but at the local polling places. This process was similar to voting by mail in that citizens received official leaflets informing them about the applicants and then cast secret ballots to approve or reject the applications.

Representative Democracy: Naturalization requests are not decided by citizens but by elected politicians who vote on the applications in the legislative or executive branch of the municipal council (the legislative branch is called the municipality parliament in larger municipalities). Politicians are elected to serve in the council for a tenure of typically 4 years, and there are no term limits. A few municipalities elect council members for 6 years and restrict the tenure to a maximum of three terms.

Appointed Commissions: In a very small number of municipalities, the naturalization decision is delegated to appointed naturalization commissions that operate at the municipal or in some cases the cantonal level. Members are typically appointed by the municipality or cantonal council for long, and sometimes even unlimited, tenures and include a mix of local politicians and regular citizens.

Figure 1 displays the proportion of municipalities that used direct democracy, representative democracy, and appointed commissions over the period from 1990 to 2010 . The data are based on a survey we conducted with a representative sample of about 1,400 municipalities to measure the local naturalization regime. ${ }^{1}$ In the early 1990s, approximately $79 \%$ of the municipalities used direct democracy, $20 \%$ used representative democracy, and only about $1 \%$ used appointed commissions to vote on naturalization requests. Barely any institutional change occurred from the 1990s to about 2005, when, triggered by a series of landmark rulings by the Swiss Federal Court, about 600 municipalities were forced to transfer the decision-making authority over naturalization applications from voters to politicians.

This switch to representative democracy was driven by multiple Federal Court rulings. In the early 2000s, media reports sparked debates about seemingly discriminatory rejections of applicants in one of the ballot box municipalities that voted on naturalization applications in secret ballot referendums. A case was brought before the Federal Court, which, in July 2003, ruled that secret ballot voting for naturalization referendums violates the Swiss Constitution (BGE 129 I 232 and BGE 129 I 217). The main reason for ruling out secret ballot referendums was that immigrants have the right to appeal rejected applications; therefore, the decision-making body is obligated to provide a justification for a rejection (BGE 129 I 217). Since it lies in the nature of closed ballots that voters do not have to justify their decisions, the court reasoned that such procedures cannot be used for naturalizations (see the supporting information [SI] for details).

Through these rulings, the Federal Court considerably narrowed the range of permissible institutional regimes that municipalities could use to vote on naturalization applications. As a direct response, the ballot box municipalities immediately had to transfer the authority for naturalization decisions to the municipality council. Many of the other direct democratic municipalities that

\footnotetext{
${ }^{1}$ We provide details about the survey in the next section. Table B.1 in the supporting information provides a detailed breakdown for the different regime subtypes.
} 


\section{FIGURE 1 Trends in Naturalization Institutions}

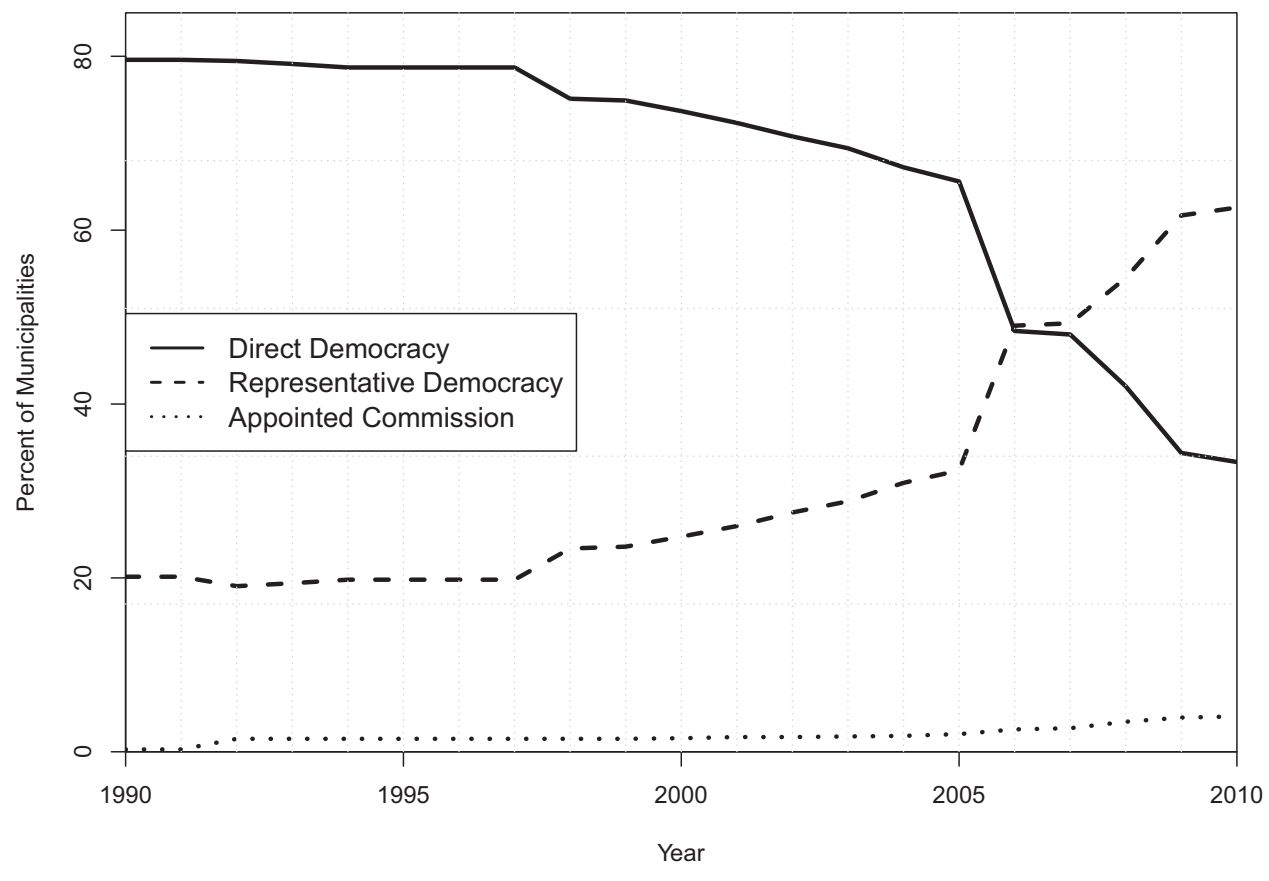

Source: Authors' municipality survey.

Note: Plot shows percent of municipalities that use direct democracy, representative democracy, and appointed commissions to decide on local naturalization requests for the years $1990-2010$. $N=1,360$ municipalities.

voted at the citizens' assemblies initially tried to accommodate the court rulings, which required municipalities to justify rejections, by arguing that any concerns that were raised about applicants during the assembly meeting could be used as an ex post justification for rejections. However, in 2004, the Federal Court issued another ruling (BGE 130 I 140) and argued that such a practice of providing expost justifications was constitutionally problematic and clarified that it would be tolerated only as a temporary solution until municipalities and cantons revised their naturalization procedures. This landmark ruling triggered a larger institutional change, as direct democracy municipalities that voted at the citizens' assemblies were compelled to transfer the decision-making power over naturalization requests to the municipality council. Several cantons, mainly larger ones with numerous naturalization requests, immediately drafted new laws regulating the institutional procedures for granting citizenship. Particularly, the cantons of Bern, Vaud, and Zurich issued laws in 2005 requiring that naturalizations be decided by the municipal council.

The court rulings and resulting cantonal reforms forced municipalities to switch from direct to representative democracy, therefore provide a fitting natural experiment to identify the causal effect of the institution.
In particular, we can exploit the over-time variation in about 600 municipalities because the timing of the switch from direct to representative democracy was exogenously dictated from above and not self-selected by the municipalities. Interviews that we conducted with head secretaries of a random sample of switching municipalities corroborate the exogeneity of the municipal switches. As one secretary expressed, "this change was forced upon us from above, we did not switch voluntarily." Other replies included statements like "the new laws dictated that we change the regime" or "the change was inevitable because of the new rules." Consistent with this identification strategy, placebo tests that we present below confirm that for the switching municipalities, there were no differential trends in naturalization rates for each of the 5 years prior to the switch.

\section{Data, Sample, and Methodology}

We collected annual panel data for the 1990-2010 period for a large sample of Swiss municipalities. The SI contains details and sources for all measures. The key independent variable is the institutional regime that municipalities use to decide on their naturalization applications. We use 
two binary variables, Direct Democracy and Appointed Commission, that we coded as 1 if a municipality $i$ used direct democracy or an appointed commission, respectively, as of January 1 in a given year $t$, and 0 otherwise. Representative Democracy serves as the reference category. To measure these institutions, we fielded a survey to the head secretaries (Gemeindeschreiber) of all Swiss municipalities to collect information about the history of the local naturalization process. This survey yielded an overall response rate of about $60 \%$, for a total sample size of 1,476 municipalities. The nonresponse analysis suggested that our sample is representative of the target population. The sample municipalities capture about $82 \%$ of the total Swiss population or $75 \%$ of municipalities with at least 10 naturalizations in 2000.

The outcome is the naturalization rate, which for each municipality is defined as the number of ordinary naturalizations that occurred during year $t$ divided by the number of eligible foreigners who resided in the municipality at the beginning of year $t$. We computed the local naturalization rates using the detailed Foreign Population Structure and Migration Statistics (PETRA) register data provided to us by the Swiss Federal Statistical Office. Table B.2 in the SI provides descriptive statistics.

To estimate the effect of direct democracy, we use a two-way fixed effects regression given by

$$
\begin{aligned}
Y_{i t}= & \eta_{i}+\delta_{t}+\alpha \text { Direct Democracy }_{i t} \\
& +\gamma \text { Appointed Commission }_{i t}+X_{i t}^{\prime} \beta+\varepsilon_{i t},
\end{aligned}
$$

where $Y_{i t}$ is the local naturalization rate, $\eta_{i}$ is a municipality fixed effect that rules out omitted variable bias from unobserved municipality characteristics that are time invariant over our period (e.g., a municipality's geographic features, its political culture and history), $\delta_{t}$ is a year fixed effect to control for common factors that change nonlinearly over our period (e.g., federal trends in migration), Direct Democracy $_{i t}$ and Appointed Commission ${ }_{i t}$ are our institutional measures, $X_{i t}$ is a vector of time-varying covariates, including a constant, and $\varepsilon_{i t}$ is an idiosyncratic error term. The quantity of interest is $\alpha$, which identifies the effect of switching from direct to representative democracy based on the within-municipality variation of naturalization rates among municipalities that switch their regimes over time. In other words, the requirement for the identification is that the timing of the institutional switch is exogenous to the municipalities, which is plausible because the timing of the institutional shift is not self-selected, but forced upon the municipalities by the federal court ruling and the subsequent cantonal reforms, which were beyond the control of the municipalities.
In the robustness checks, we further relax the model specification and estimate

$$
\begin{aligned}
Y_{i t}= & \eta_{i 0}+\eta_{i 1} t+\eta_{i 2} t^{2}+\delta_{t}+\alpha \text { Direct Democracy }_{i t} \\
& +\gamma \text { Appointed Commission } \\
i t & +X_{i t}^{\prime} \beta+\varepsilon_{i t},
\end{aligned}
$$

where $t$ is a time trend variable. This specification includes municipality fixed effects, year fixed effects, and municipality-specific linear and quadratic time trends. The addition of the municipality-specific trends ensures that unobserved municipality-specific differences that vary smoothly over time (e.g., local trends in voter preferences, ethnic heterogeneity, or migration patterns) are purged from the estimate of $\alpha$, such that only breaks in the trends of the local naturalization rates that directly coincide with the switching from direct to representative democracy are captured by this parameter. Our effect estimates remain very similar when adding the municipality-specific time trends, which yields support to our identification assumption that the timing of the institutional switch is exogenous to the municipal trends. We also use additional specifications and placebo checks, including a dynamic panel model that shows that the switching municipalities exhibit no differential trends in the 5 years prior to the switch, which further corroborates the validity of the identifying assumption. To account for potential serial correlation and heteroskedasticity, we always cluster the standard errors at the municipal level. To address potential posttreatment bias, we present the results both with and without time-varying covariates.

\section{Does Direct Democracy Hurt Immigrant Minorities?}

We first conduct a nonparametric graphical analysis that, akin to a regression discontinuity design, seeks to isolate the extent to which the differences in naturalization rates can be attributed to the effect of switching from direct to representative democracy. In Figure 2, we plot the naturalization rates for the 7 years before and after the municipalities switched from direct to representative democracy as gray dots (the values are jittered horizontally). The sample is restricted to the switching municipalities, and the municipalities are arranged such that year zero refers to the first year in which the municipalities used representative democracy to decide on naturalization requests as of January 1 . The solid and dashed lines summarize the average naturalization rate in the years under direct and representative democracy, respectively (based on a loess fit with $95 \%$ pointwise confidence intervals). 


\section{FIGURE 2 Effect of Direct Democracy on Naturalization Rates}

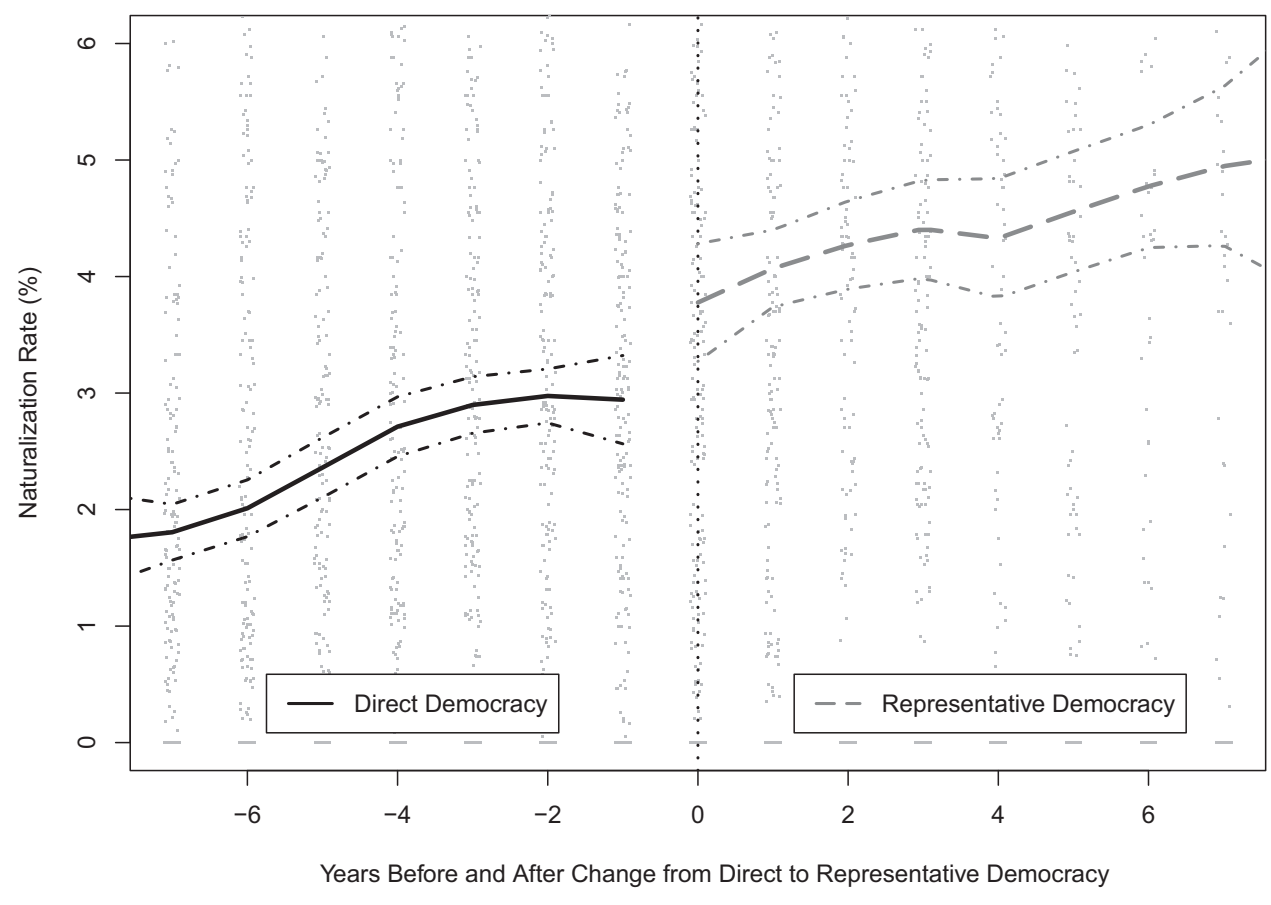

Note: Plot shows how ordinary naturalization rates change as municipalities switch from direct to representative democracy. Gray dots visualize municipal naturalization rates for 7 years before and after a given municipality switched from direct to representative democracy (values are horizontally jittered); year 0 refers to the first year in which representative democracy was used on January 1 . The solid and dashed lines summarize the average naturalization rate in the years under direct and representative democracy, respectively, using a loess fit (solid line) with $95 \%$ pointwise confidence intervals (dotted line). $\mathrm{N}=598$ (all switching municipalities).

The results provide evidence that the average naturalization rate surged sharply just as municipalities switched from direct to representative democracy. A signed rank test comparing the naturalization rates to the left and the right of the threshold reveals that this jump is significant at conventional levels $(\mathrm{p}<.03)$. The fact that the steep rise in the naturalization rates coincides with the institutional switch suggests that this increase is attributable to the change from direct to representative democracy as opposed to other confounding factors. Given that it takes about 3-5 years of processing time before a submitted application is put to a vote, immigrants had no way of anticipating the switch in the institutional regime; therefore, the increase in naturalization rates cannot be explained by a sudden increase in the quality of the applicant pool. Instead, lucky immigrants whose naturalization applications were to be evaluated by elected politicians in the council stood a much better chance of getting a Swiss passport as compared to unlucky, but similarly qualified, applicants who had submitted their nat- uralization applications in the same municipality just a few months earlier such that their requests would still be decided by voters under direct democracy.

Table 1 presents the results from the two-way fixed effects specification. The coefficient on the Direct Democracy indicator in Model 1 reveals that switching from direct to representative democracy increased naturalization rates by 1.22 percentage points on average. This effect is precisely estimated $(t \approx 6.8)$ and large in substantive terms. As reported in the last three rows in Table 1, the switch from direct to representative democracy resulted in an increase of approximately $61 \%$ over the average naturalization rate under direct democracy, with a $95 \%$ confidence interval of [44\%, 79\%].

Model 2 adds a second indicator, Appointed Commission, for the very small group of municipalities where applications are evaluated by appointed naturalization commissions. The results suggest that naturalization rates are higher under this regime compared to representative democracy. However, this effect is based on a very small 
TABLE 1 Effect of Direct Democracy on Naturalization Rates

\begin{tabular}{|c|c|c|c|c|}
\hline Outcome & & Natu & $(\%)$ & \\
\hline Mean (Direct Democracy) & & & & \\
\hline Sample & & & & \\
\hline Model & (1) & (2) & (3) & (4) \\
\hline Direct Democracy & $\begin{array}{c}-1.22 \\
(0.18)\end{array}$ & $\begin{array}{c}-1.21 \\
(0.18)\end{array}$ & $\begin{array}{r}-1.72 \\
(0.22)\end{array}$ & $\begin{array}{c}-1.71 \\
(0.23)\end{array}$ \\
\hline Appointed Commission & & $\begin{array}{c}0.51 \\
(0.58)\end{array}$ & & $\begin{array}{c}0.11 \\
(0.71)\end{array}$ \\
\hline Constant & $\begin{array}{l}1.80 \\
(0.16)\end{array}$ & $\begin{array}{c}1.79 \\
(0.16)\end{array}$ & $\begin{array}{c}2.40 \\
(0.23)\end{array}$ & $\begin{array}{c}2.39 \\
(0.23)\end{array}$ \\
\hline $\begin{array}{l}\text { Municipality Fixed Effects } \\
\text { Year Fixed Effects }\end{array}$ & $\begin{array}{l}\sqrt{ } \\
\sqrt{ }\end{array}$ & $\begin{array}{l}\sqrt{ } \\
\sqrt{ }\end{array}$ & $\begin{array}{l}\sqrt{ } \\
\sqrt{ }\end{array}$ & $\begin{array}{l}\sqrt{ } \\
\sqrt{ }\end{array}$ \\
\hline Observations & 24,484 & 24,484 & 15,661 & 15,661 \\
\hline Municipalities & 1,360 & 1,360 & 877 & 877 \\
\hline Effect Size $(\% \Delta)$ & 62 & 60 & 78 & 78 \\
\hline 95\% CI LB & 44 & 42 & 58 & 58 \\
\hline 95\% CI UB & 79 & 78 & 98 & 98 \\
\hline
\end{tabular}

Note: OLS panel fixed effects regression for 1991-2009 period. Regression coefficients are shown, with robust standard errors (clustered by municipality) in parentheses. The outcome variable is the municipal rate for ordinary naturalizations, and the independent variables are Direct Democracy ( 1 for direct democracy, 0 otherwise) and Appointed Commission ( 1 for appointed commission, 0 otherwise). Representative democracy is the baseline. The last three rows summarize the increase when switching from direct democracy to representative democracy as the percent increase over the average naturalization rate under direct democracy. LB and UB refer to upper and lower bounds of the $95 \%$ confidence interval. Models 1-2 refer to the sample of all municipalities, and Models 3-4 restrict the sample to municipalities in the German-language region.

number of municipalities and is not per se identified by our natural experiment. Not surprisingly, it is also not robust across specifications. Models 3 and 4 replicate these specifications while restricting the sample to municipalities in the German-language region where the large majority of switches occurred. The results are similar, with slightly larger effect sizes: On average, switching from direct to representative democracy increased naturalization rates by about $78 \%[58 \%, 98 \%]$.

Overall, the results demonstrate that applicants fare better if elected politicians in municipal councils rather than the citizens in referendums decide naturalization requests. A back-of-the-envelope calculation suggests that, in the switching municipalities alone, about 12,000 fewer immigrants would have been naturalized over the last 5 years if municipalities had not switched to representative democracy (based on the estimate in Model 1). This is a rather conservative calculation since it is only based on switching municipalities and ignores the fact that the long-term effects of the switch are even larger (see below).

How robust are these findings? Here, we summarize a variety of robustness checks. First, we checked whether our results are robust to including time-varying covari- ates and municipality-specific time trends that proxy for time-varying unobserved confounders. The set of timevarying covariates includes economic shocks, captured by the local unemployment rate; demographic shocks, captured by the log population and lagged ratio of the Swiss to the foreign-born population; and preference shocks, captured by the municipality-level vote shares for the Swiss People's Party (SVP). This vote share variable provides a good proxy for the xenophobic preferences of the local electorate because the SVP is the main right-wing party in Switzerland, and its political agenda is anti-immigration (Kriesi et al. 2005). Table B.3 in the SI shows that the results are highly robust across all specifications; on average, direct democracy decreases the naturalization rate by approximately $54-78 \%$, and this effect is precisely estimated across models. This reassures us that the effect of direct democracy is not driven by global or local trends in unobserved confounders. This also rules out the possibility that the effect might have resulted from a general impact of the court rulings on naturalization decisions. Consistent with this, we also found that municipalities that did not switch did not experience any unusual increase in naturalization rates around the time of the court rulings. 
Second, we investigated whether our results are sensitive to the fact that some municipalities did not change their regime during our time period. These municipalities are in cantons that had not revised their regulations by 2010; therefore, municipalities in these cantons had not yet been forced to switch. These municipalities should not influence the internal validity of our effect estimates because our identification is based only on municipalities that were forced to switch as a result of the new regulations triggered by the court rulings. To test this, we replicated the benchmark model for two subsamples, which comprise (1) the municipalities in cantons where the majority of the municipalities switched from direct to representative democracy and (2) only the municipalities that switched from direct to representative democracy. The results, which are displayed in Table B.4 in the SI, are very similar to the main results across all models, with effect sizes ranging from 56 to $78 \%$. Although this test corroborates the internal validity of our estimates, we note that the fact that some cantons have not switched yet may still influence the external validity of our estimates. In particular, given that the cantons that had not yet switched include some of the more conservative areas (Aargau, Solothurn, and Thurgau), the estimated increase in naturalization rates that we obtained from the sample of switching municipalities presumably provides an underestimate of the (potentially) larger effect expected if all municipalities were to switch to representative democracy (in the section below, we show that the effect of switching is larger in more conservative areas).

Third, we checked whether the results are different for the ballot box municipalities that were forced to switch immediately as a result of the very first federal court ruling and for the municipalities that used citizens' assemblies and had to switch as a result of the subsequent court rulings and cantonal reforms. The results, displayed in Table B.5 in the SI, show that the effects of switching from direct to representative democracy are quite similar for both groups, with effect sizes of $80 \%$ for ballot box municipalities and $72 \%$ for assembly municipalities. This further corroborates the internal validity of our estimates and rules out the possibility that the results are confined to a particular flavor of direct democracy (including forms with and without deliberation about the naturalization requests).

Fourth, we examined whether there are differential trends prior to the switch and whether switching had different short-term and long-term effects. For this, we estimated a dynamic panel model in which we coded a binary indicator that captures the change from direct to representative democracy and added five leads and three lags of this indicator to capture the potential effects during the 5 years before and the 3 years following the actual switch (the model also includes a full set of municipality and year fixed effects). In Figure 3, we plot the effects for the leads and lags (with their $95 \%$ confidence intervals).

The results provide evidence that the transition from direct to representative democracy considerably increased naturalization rates. We find no significant "placebo" effects for the 5 years leading up to the switch, which corroborates that there are no omitted variables that lead to differential trends prior to the adoption of representative democracy, as we would expect given that the switch was exogenous to the municipalities. Significant differences in naturalization rates emerge immediately after the regime change, and these differences grow considerably larger, with estimated increases of up to $115-130 \%$ during the 3 years following the transition. This demonstrates that the shift from direct to representative democracy resulted in considerably higher naturalization rates in the long term. It stands to reason that the general equilibrium effects of the switch in the longer term are even bigger than what we can capture here with our limited time period. Since it is now easier to get approved under representative democracy, we might expect that the pool of applicants will increase in the longer term, as immigrants who are otherwise discouraged from applying will submit their applications once they learn about how the regime change has affected the naturalization decisions.

As a final robustness check, we replicated our models using the rate of facilitated naturalizations in the municipality as the dependent variable instead of the rate of ordinary naturalizations, which is by far the most common mode of naturalization. Facilitated naturalizations, which can be applied for only by those immigrants who have been married to a Swiss citizen for at least 5 years, are an ideal placebo outcome: Facilitated and ordinary naturalizations typically follow a similar dynamic because they are influenced by many of the same demand and supply factors. However, they differ in that the treatment variable is "switched off" for the facilitated naturalizations since they are centrally decided by the Federal Office for Migration and the municipalities are not involved in the decision. Therefore, switching from direct to representative democracy should have no effect on this placebo outcome unless there are time-varying omitted variables that coincide with the switch and cause a change in the local naturalization rate. Figure 4 replicates the dynamic panel model and confirms that the switch from direct to representative democracy had no discernible effect on the rate of facilitated naturalizations; the point estimates are precisely estimated zeros for the differential trends prior to the switch, the short-term effects, and the long-term effects. Table B.6 in the SI shows that the same is true 


\section{Figure 3 Dynamic Effect of Direct Democracy on Naturalization Rates}

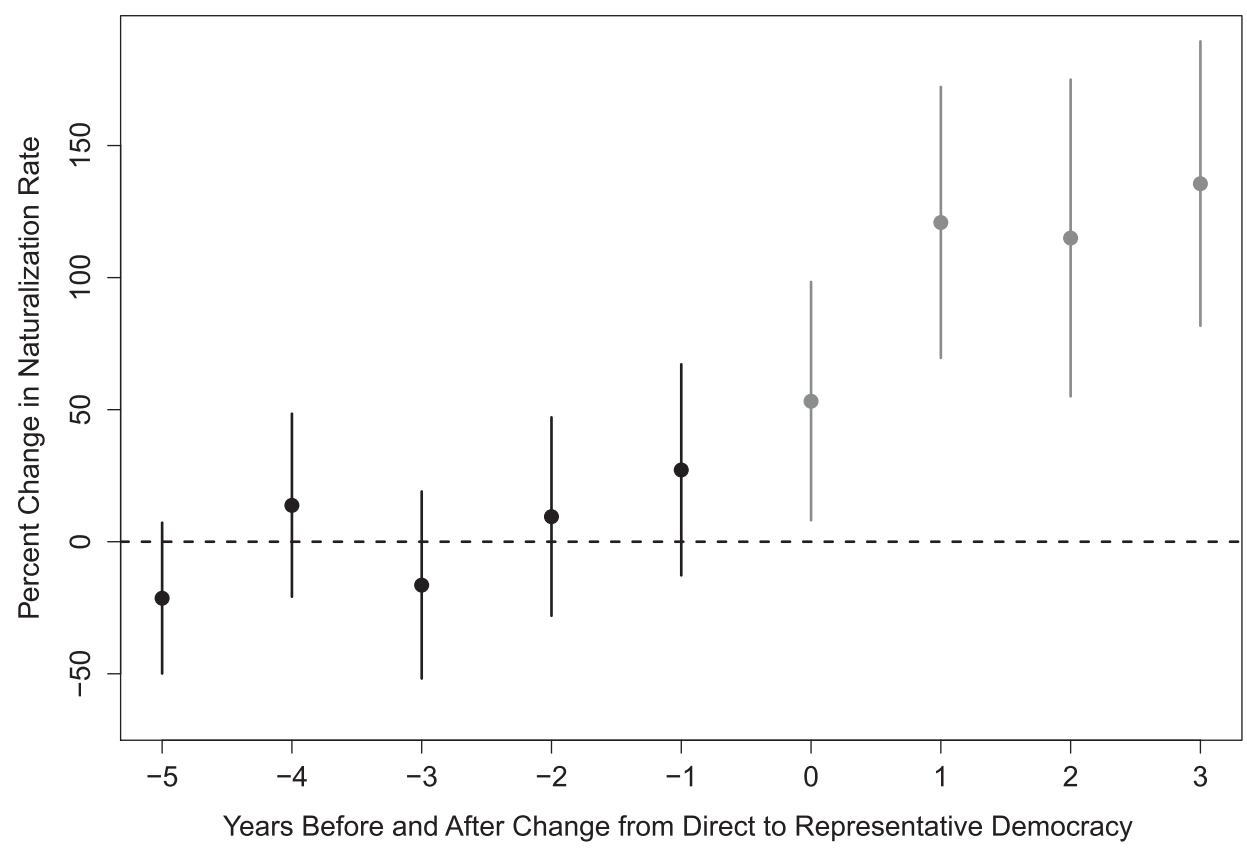

Note: Estimated impact of switching from direct to representative democracy on ordinary naturalization rate for years before (black lines) and after (gray lines) the institutional change. Year 0 is the first year in which representative democracy was used on January 1. Point estimates with $95 \%$ confidence intervals (based on robust standard errors clustered by municipality) are from dynamic panel regression including municipality and year fixed effects and indicator variables for three lags and five leads. Results are based on $N=487$ switching municipalities for which complete panels are available. Notice that the (insignificant) positive difference for the year immediately prior to the reform, year -1 , is mostly an artifact of our conservative coding. Since we measure the institutional regime on January 1 of each year, year 0 refers to the first full year under representative democracy and year -1 , although coded as preceding the switch, is in fact a hybrid because it includes several municipalities that switched early or in the middle of the year such that their naturalization rates for year -1 include many naturalizations that were already decided under representative democracy.

for the other subsamples. These results suggest that the main results are not driven by shocks in unmeasured confounders.

\section{Why Do Immigrants Fare Worse under Direct Democracy?}

Our natural experiment provides evidence that switching from direct to representative democracy increased the naturalization rates of immigrant minorities. What mechanisms might explain this institutional effect? It is well known that isolating the precise mechanisms that underly any causal effect is very difficult with observational (and even experimental) data. Nonetheless, in the following, we provide evidence that speaks to the relative importance of four potential channels involving differences in the processing time, levels of information, preferences, and legal accountability. This evidence draws on further quantitative tests as well as over 230 semi-structured interviews that we conducted with the head secretaries of a random sample of the switching municipalities (see the SI for details).

A first hypothesis is that the switch from direct to representative democracy led to higher naturalization rates through a sharp decrease in the processing time. This hypothesis implies that the switch should produce an instantaneous short-term effect; however, once the naturalization rate stabilizes at the increased rate, no long-term 


\section{Figure 4 Dynamic Effect of Direct Democracy on Facilitated Naturalization Rates (Placebo Outcome)}

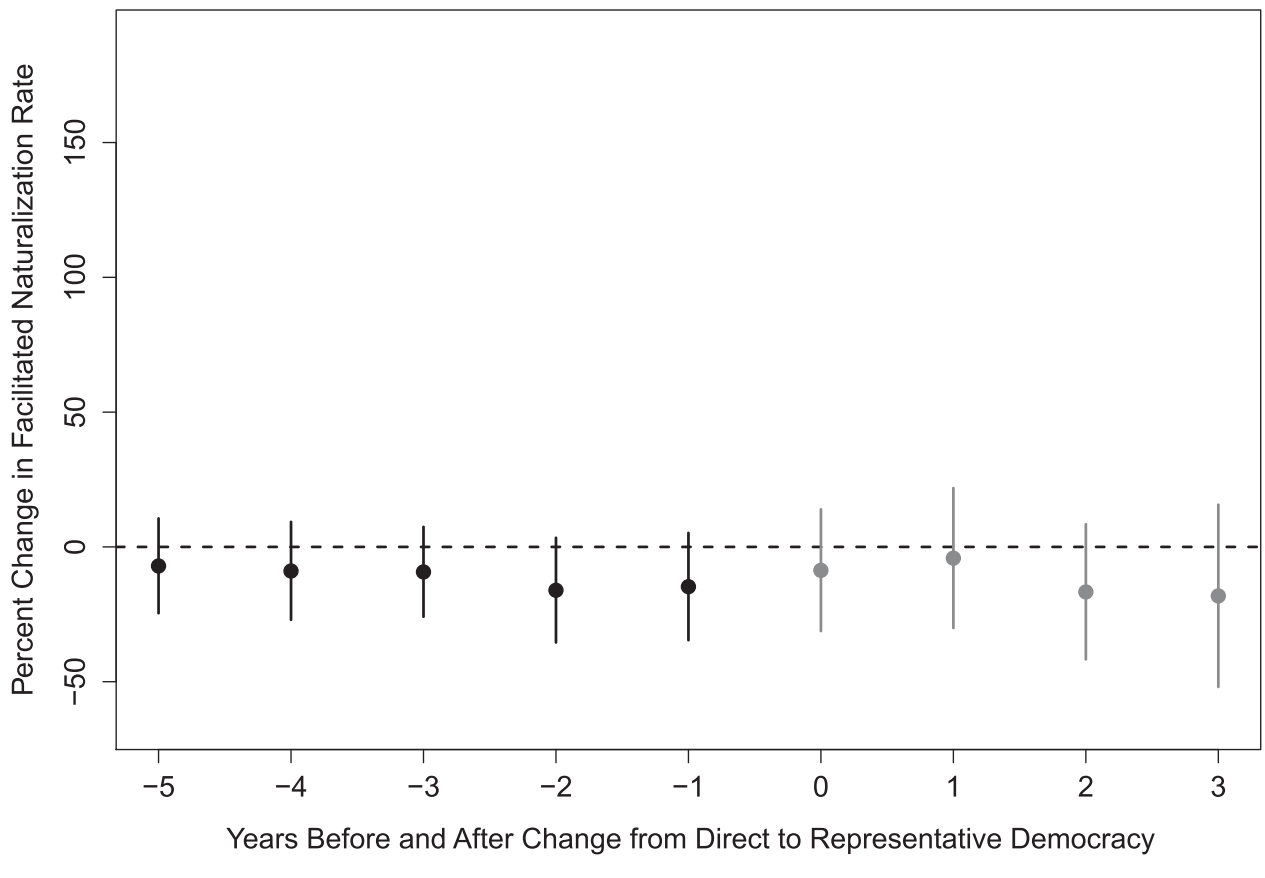

Note: Estimated impact of switching from direct to representative democracy on facilitated naturalization rate for years before (black lines) and after (gray lines) the institutional change. Year 0 is the first year in which representative democracy was used on January 1. Point estimates with $95 \%$ confidence intervals (based on robust standard errors clustered by municipality) are from dynamic panel regression including municipality and year fixed effects and indicator variables for three lags and five leads. Results are based on $N=487$ switching municipalities for which complete panels are available.

effects should be evident. The dynamic panel estimates in Figure 3, which show that the long-term effects are even larger than the immediate effects, contradict this implication.

A second mechanism is that elected politicians may reject fewer applicants than voters because they have more information about the applicants. This explanation also lacks empirical support. Although council members typically have substantial information about the applicants, the same was often true for citizens who voted on the applications under direct democracy. In the ballot box municipalities, voters received voting leaflets, which provided a detailed description of each applicant, prior to the referendums. Similarly, in municipalities where voting occurred at the citizens' assemblies, applicants often had to appear at the assembly and were interviewed by the voters. Even if we do assume that politicians have more information, it is not clear why this would lead them to reject fewer applicants unless we can explain why they would positively evaluate such information.
A third hypothesis is that the effect of switching might be driven by differences in the preferences of voters and politicians. Since decisions are made by majority rule, we have to consider the preferences of the median voters and the median politicians who decide the naturalization votes in the referendums or the municipality councils, respectively. One possibility is that the median politicians in the legislatures are more pro-immigration compared to the median voters, and therefore we see fewer rejections once municipalities switch from direct to representative democracy. This hypothesis is difficult to evaluate because there exists no detailed systematic data on the preferences of local politicians that could be directly compared to the preferences of the local electorate. However, given that the politicians in the council are elected by the voters in the municipality in competitive elections, standard models of representation (Downs 1957) suggest that the preferences of the median politician in the council should roughly reflect the preferences of the median voter in the electorate. In other words, if electoral competition works 


\section{FIGURE 5 Effect of Direct Democracy on Naturalization Rates by Country of Origin}

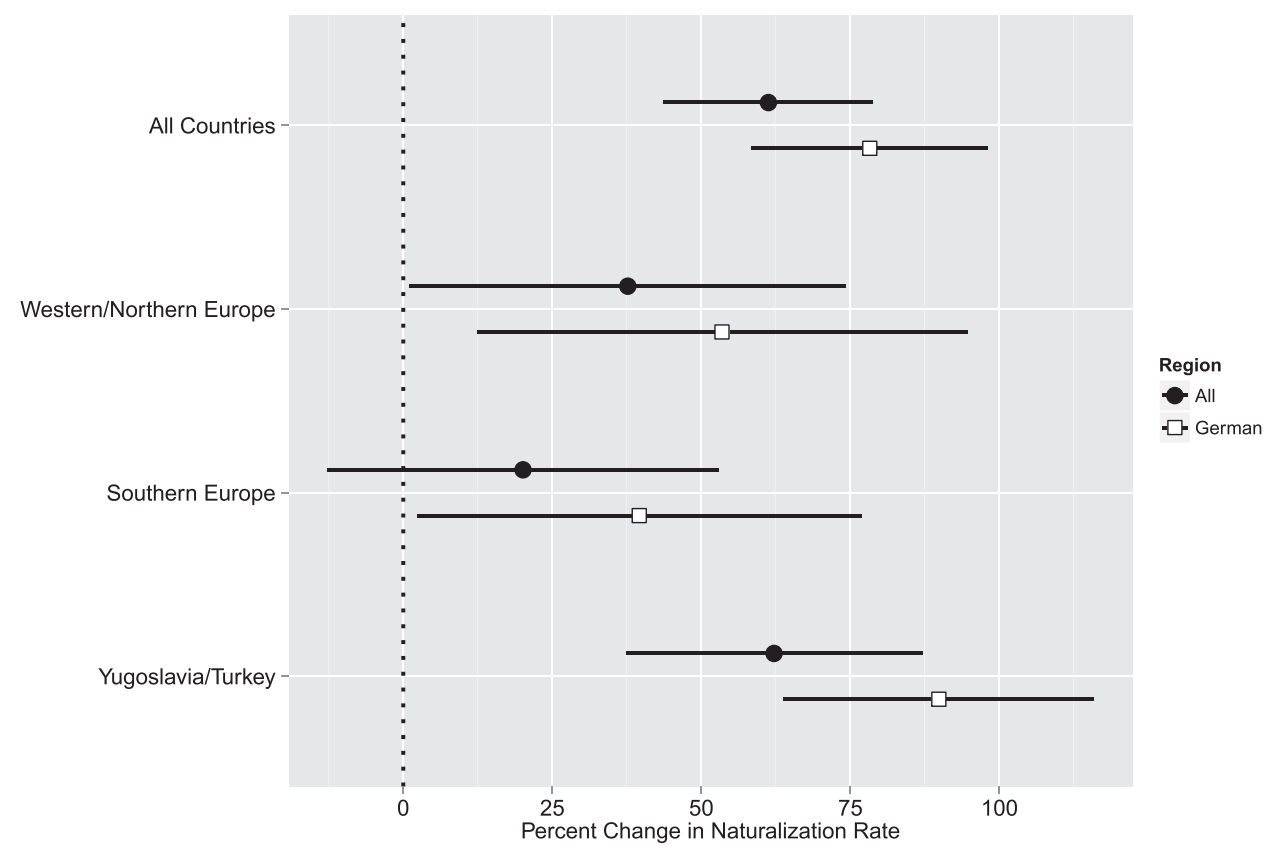

Note: Effect of switching from representative to direct democracy on ordinary naturalization rate, computed for applicants from different country of origin groups (based on Models 1 and 2 in Table 1 and Models 1-6 in SI Table B.9).

and voters elect politicians who share their preferences, then we would expect that in municipalities where the median voter is anti-immigrant, the median politician in the council should be equally anti-immigrant. Consistent with such a model of representation, we find that the seat shares of the SVP in the municipality councils, a rough proxy for the immigration preferences of the median voter, are highly correlated with the local vote share for the SVP in federal elections, a proxy for the immigration preferences of the median voter (see SI Figure B.3). Therefore, it seems theoretically and empirically doubtful that there exists large differences in the preferences of the median voter and the median politician that could account for the large effect of the shift from direct to representative democracy. That said, below we also consider more sophisticated versions of the preference hypothesis that allow for differences in the preferences of the median voter and the median politician. These alternative versions of the preference mechanism also receive no empirical support.

The fourth mechanism we examined holds that even though the median politician and the median voter share roughly similar preferences and would like to reject a roughly similar fraction of applicants, politicians face a higher level of legal accountability and therefore higher costs for engaging in potentially arbitrary rejections. Notice that by legal accountability, we refer to the accountability between the decision maker and the law, not the political accountability of elected politicians to voters. In both regimes, either citizens or politicians are granted the authority to decide on the naturalization applications; however, the discretion of the decision maker is legally constrained by the normative requirement that the application decision has to be made on nondiscriminatory grounds. In particular, Swiss law stipulates that applicants can be rejected on the basis of certain permissible criteria (e.g., insufficient language skills or integration status), but it is illegal to reject applicants on the basis of certain impermissible criteria (e.g., origin, ethnicity, or religion).

Although in theory voters are subject to the same normative requirements as politicians, in practice this legal accountability relationship between the decision maker and the law functions poorly under direct democracy since there is no institutional mechanism in place to ensure that voters obey the requirement to exercise their decision-making authority only in a nondiscriminatory way. In referendums, citizens do not have to justify why they reject an applicant, and they cannot legally be held accountable for discriminatory rejections. Voters are 


\section{FiguRe 6 Effect of Direct Democracy and Voter Preferences}

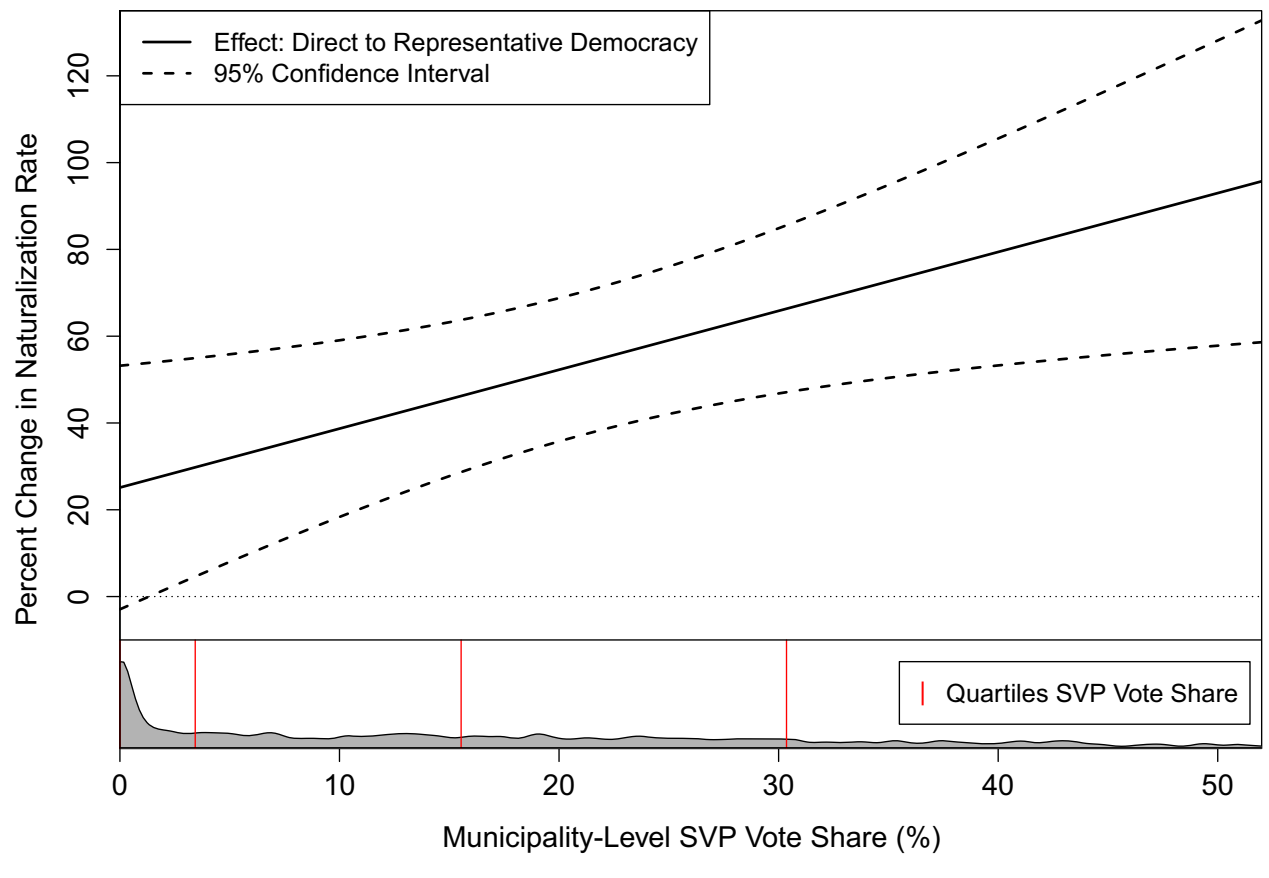

Note: Marginal effect of switching from direct to representative democracy on the ordinary naturalization rate computed at different levels of SVP vote share (based on Model 1 in SI Table B.7). The gray shaded area visualizes the density of the marginal distribution of SVP vote shares; red vertical lines indicate the quartiles.

unconstrained to "sincerely" vote on their personal preferences and arbitrarily reject applicants based on their origin or other impermissible criteria. In contrast, the legal accountability relationship functions better under representative democracy because politicians holding elected office are required to publicly report on the grounds on which they reject an applicant, and they might be held accountable for arbitrary rejections if a rejected applicant appeals to the courts, which then review the justification for the rejection. These mechanisms constrain the discretion of politicians and make it more costly for them to disobey the requirement for nondiscriminatory decisions. This does not mean that application decisions are always discriminatory under direct democracy or always free from discrimination under representative democracy, but it does suggest that, even when the median politician in the council might be just as prejudiced against immigrants as the median voter, the heightened legal accountability that the politician faces makes it less likely that he will "sincerely" act upon his potentially prejudicial preferences and arbitrarily reject an applicant on discriminatory grounds.

What is the empirical evidence for this legal accountability mechanism? There are at least five observable im- plications that we can evaluate with our data. First, if this mechanism is important, we would expect head secretaries to mention it in the interviews. This is indeed the case. For example, when asked about potential reasons why the naturalization rate was lower under direct democracy, answers included statements such as 'in the citizens' assemblies, decisions were often based on pure populism and applicants were arbitrarily rejected based on emotional gut decisions and prejudice: this is a Yugo and we don't like him"; "flawless applicants were sometimes rejected simply because people vented their frustrations"; or "assembly votes were extremely emotional, based on sympathy or nationality." When asked about why the naturalization rate might have increased following the switch to representative democracy, responses included statements such as "there is much less discrimination in the council, as politicians have to carefully justify a rejection and can be held accountable"; "legislators have to look at facts and cannot afford to decide based on emotions like the voters"; "politicians have much less room for arbitrariness, they cannot vote against Yugoslavian applicants on principle"; or "legislators are aware that arbitrary rejections might be challenged in court." In summary, more than two-thirds (25 out of 37 ) of the interviewed secretaries 


\section{TABle 2 Successful Appeals and Average Naturalization Rates under Representative and Direct Democracy}

\begin{tabular}{|c|c|c|c|c|c|c|c|c|}
\hline \multirow{2}{*}{$\begin{array}{l}\text { Outcome } \\
\text { Sample }\end{array}$} & \multicolumn{4}{|c|}{ Naturalization Rate $(\%)($ Mean $=6.15)$} & \multicolumn{4}{|c|}{ Naturalization Rate $(\%)($ Mean $=5.59)$} \\
\hline & \multicolumn{4}{|c|}{ Representative Democracy } & \multicolumn{4}{|c|}{ Direct Democracy } \\
\hline $\begin{array}{l}\text { Appeals Relative } \\
\text { to }\end{array}$ & \multicolumn{2}{|c|}{$\begin{array}{c}\text { Eligible } \\
\text { Immigrants }\end{array}$} & \multicolumn{2}{|c|}{ Municipality Size } & \multicolumn{2}{|c|}{ Eligible Immigrants } & \multicolumn{2}{|c|}{ Municipality Size } \\
\hline Model & (1) & (2) & (3) & (4) & (5) & (6) & (7) & (8) \\
\hline $\begin{array}{c}\text { Relative \# of } \\
\text { Appeals }\end{array}$ & $\begin{array}{c}0.19 \\
(0.04)\end{array}$ & & $\begin{array}{c}0.28 \\
(0.07)\end{array}$ & & $\begin{array}{c}0.04 \\
(0.12)\end{array}$ & & $\begin{array}{c}0.03 \\
(0.20)\end{array}$ & \\
\hline $\begin{array}{l}\text { Medium \# of } \\
\text { Appeals }\end{array}$ & & $\begin{array}{c}-0.40 \\
(0.62)\end{array}$ & & $\begin{array}{c}-0.02 \\
(0.67)\end{array}$ & & $\begin{array}{c}-1.35 \\
(1.43)\end{array}$ & & $\begin{array}{c}-1.40 \\
(1.46)\end{array}$ \\
\hline High \# of Appeals & & $\begin{array}{c}2.42 \\
(0.77)\end{array}$ & & $\begin{array}{c}2.10 \\
(0.84)\end{array}$ & & $\begin{array}{c}0.86 \\
(1.41)\end{array}$ & & $\begin{array}{c}0.79 \\
(1.41)\end{array}$ \\
\hline Constant & $\begin{array}{c}6.69 \\
(0.52)\end{array}$ & $\begin{array}{c}6.70 \\
(0.52)\end{array}$ & $\begin{array}{c}6.62 \\
(0.51)\end{array}$ & $\begin{array}{c}6.63 \\
(0.50)\end{array}$ & $\begin{array}{c}5.95 \\
(0.84)\end{array}$ & $\begin{array}{c}6.06 \\
(0.79)\end{array}$ & $\begin{array}{c}5.98 \\
(0.79)\end{array}$ & $\begin{array}{c}6.07 \\
(0.77)\end{array}$ \\
\hline $\begin{array}{l}\text { Municipality } \\
\text { Fixed Effects }\end{array}$ & $\sqrt{ }$ & $\sqrt{ }$ & $\sqrt{ }$ & $\sqrt{ }$ & $\sqrt{ }$ & $\sqrt{ }$ & $\sqrt{ }$ & $\sqrt{ }$ \\
\hline Year Fixed Effects & $\sqrt{ }$ & $\sqrt{ }$ & $\sqrt{ }$ & $\sqrt{ }$ & $\sqrt{ }$ & $\sqrt{ }$ & $\sqrt{ }$ & $\sqrt{ }$ \\
\hline Observations & 250 & 250 & 251 & 251 & 79 & 79 & 79 & 79 \\
\hline Municipalities & 61 & 61 & 61 & 61 & 35 & 35 & 35 & 35 \\
\hline
\end{tabular}

Note: OLS panel fixed effects regression for 2004-10 period. The sample consists of municipalities from the cantons of Zurich and Bern under representative democracy (Models 1-4) and direct democracy (Models 5-8). Regression coefficients are shown, with robust standard errors (clustered by municipality) in parentheses. The outcome variable is the municipal rate for ordinary naturalizations, and the independent variables are the continuous measure for lagged successful appeals (Models 1,3, 5, and 7) and the categorical measure for lagged successful appeals (Models 2, 4, 6, and 8). Models 1, 2, 5, and 6 utilize the number of successful appeals relative to the number of eligible immigrants; Models 3, 4, 7, and 8 utilize the number of successful appeals relative to the municipality size.

who talked about potential mechanisms explaining the increase in naturalization rates stated that the responsibility of the municipal council to justify a rejection "plays a major role."

Second, if the legal accountability mechanism is important, we expect a fair share of arbitrary rejections under direct democracy given that voters casting secret ballots face few constraints to vote on their prejudice. This implication is also supported by the evidence. Hainmueller and Hangartner (2013) analyzed naturalization referendums in ballot box municipalities over the 19702003 period and found that they were largely decided based on the applicant's country of origin. For example, the most marginalized group of applicants from the former Yugoslavia or Turkey obtained an approximately $40 \%$ higher proportion of "no" votes on average compared to observably similar applicants from Western or Northern European countries. In contrast, permissible criteria, such as the applicants' language skills or integration status, had almost no effect on the outcome of the naturalization referendums.
Third, the legal accountability mechanism anticipates that switching from direct to representative democracy is most beneficial for applicants from the most marginalized groups. This is because these groups face the highest rates of arbitrary rejections under direct democracy but should enjoy more protection under representative democracy if politicians face higher legal accountability, and therefore discriminatory rejections are less likely to occur. To test for this, we replicated the benchmark two-way fixed effect model with country-of-origin-specific naturalization rates for three distinct origin groups, including immigrant applicants from (former) Yugoslavia and Turkey, Southern European countries (e.g., Italy, Spain, and Portugal), and Northern and Western European countries (e.g., Germany, Austria, and France). These origin groups account for the largest share of naturalizations; however, they vary broadly in terms of their marginalization, as immigrants from (former) Yugoslavia and Turkey typically face much higher anti-immigrant sentiments than immigrants from countries in Southern Europe (Hainmueller and Hangartner 2013). The results are displayed 
in Figure 5 and Table B.9 in the SI. We find that applicants from Yugoslavia and Turkey gained the most as municipalities switched from direct to representative democracy. In contrast, the change in the regime had no or only a small significant effect for applicants from Southern European origins. The effect estimates for the two groups are statistically significantly different $(\mathrm{p}<.05)$.

A fourth implication of the legal accountability mechanism is that the effect of switching should depend on the anti-immigrant preferences of the local electorate. Imagine a municipality where voters hold strong antiimmigrant preferences. Here, we would expect a large share of discriminatory rejections under direct democracy because the preferences of unconstrained voters directly translate into policy. However, once such a municipality is forced to switch to representative democracy, we expect the share of discriminatory rejections to drop sharply as the elected politicians, despite being just as prejudiced against immigrants as their constituents, are more constrained in acting upon their prejudice by the heightened legal accountability. On the flip side, we expect the switch to have little effect in areas with low levels of xenophobia since there should be few discriminatory rejections under either regime and legal accountability should therefore be largely irrelevant. To test this implication, we reran the benchmark model while interacting our institutional measures with the local vote share for the SVP, a proxy for the xenophobic preferences of the local electorate. The results, displayed in Figure 6 and Table B.7 in the SI, confirm that the effect of switching is indeed conditional on the xenophobic preferences of the local electorate. Switching from direct to representative democracy has essentially no effect in the least xenophobic municipalities with low SVP vote shares, but it has a large effect in the most xenophobic areas with high SVP vote shares. The results are very similar when we replicate the model while allowing for nonlinearity in the interactive effect (see Figure B.1 in the SI) or using the seat shares of the SVP in the municipality councils as an alternative measure of the preferences of the median legislator (see Figure B.2 in the SI).

Note that although the effect of heterogeneity documented above is highly consistent with the legal accountability mechanism, it is difficult to square with more sophisticated versions of the preference argument. For example, even if we assume that the median politician in the council is on average more pro-immigration than the median voter-perhaps because politicians are on average more educated and therefore more tolerant toward immigrants or less biased-then the effect of switching should be roughly uniform across immigrant groups and local levels of xenophobia. The reason is that under electoral competition, we would still expect that the preference of the median council member would at least loosely track the preference of the median voter, such that in more xenophobic municipalities, the median politician would still be more xenophobic than the median politician in less xenophobic areas (even though both politicians are generally more pro-immigration than their respective median voters). In other words, the gap in the naturalization preferences between the median voter and the median politician should be roughly similar as we move from more to less marginalized groups or from more to less xenophobic areas; therefore, this argument cannot explain why we see larger effects of the institutional shift for more marginalized groups and in more xenophobic areas.

The interaction is also difficult to square with an even more sophisticated preference argument that allows for a varying gap between the preferences of the median voter and the median politician that might emerge from a two-dimensional policy space, as in Lee, Roemer, and Straeten (2006). If anything, under such a model, we would expect the gap between the median voter and politician to be smallest in the most xenophobic municipalities since local voters there care most intensely about the immigration dimension. If voters place a high electoral weight on this dimension, we expect that the median politician will quickly adopt the strong anti-immigration position of the median voter. However, it is precisely in these places where we find the largest increase in naturalizations when switching from direct to representative democracy, which suggests that legal accountability is preventing the politician from rejecting as many applicants as voters would prefer.

The final observable implication of the legal accountability mechanism is that we might expect that politicians in the municipality council react more strongly to successful appeals by rejected applicants, which raise awareness that arbitrary rejections are indeed reviewed by the courts. In contrast, we expect that appeals have no effect under direct democracy because citizens cannot be held accountable for arbitrary rejections and therefore have no incentive to worry about judicial oversight. To test this implication, we collected data on the number of successful appeals from all municipalities in the cantons of Bern and Zurich for the years 2004-10. We first restricted the sample to years in which politicians decided on the applications and regressed the local naturalization rates on the fraction of successful appeals in the preceding year, controlling for municipality and year fixed effects.

We find that a higher fraction of successful appeals is correlated with higher naturalization rates in the next year, suggesting that politicians react to judicial oversight by engaging in fewer rejections (see Table 2, Models 1-4). 
Having a high as compared to a low fraction of successful appeals in the previous year is associated with a $40 \%$ increase in the naturalization rate compared to the average naturalization rate. ${ }^{2}$ In contrast, replicating the model for the years in which municipalities used direct democracy, we find that appeals have no effect on the naturalization rates, suggesting that voters do not react to judicial oversight; the point estimates are insignificant and fairly close to zero for all measures (see Table 2, Models 5-8). This pattern is what we would expect if politicians face higher legal accountability than voters, but it is not anticipated by the preference mechanism.

Overall, the evidence is highly consistent with the legal accountability mechanism's being an important channel through which immigrant minorities benefit from switching from direct to representative democracy. The positive effect is concentrated in the most xenophobic areas and among the most marginalized immigrant groups. Moreover, successful appeals, which raise awareness about judicial oversight, increase naturalization rates when politicians decide in the municipal council but have no effect when citizens vote on the applications in referendums. None of the alternative explanations we considered can account for these multiple patterns.

\section{Conclusion}

Direct democracy is rapidly becoming a popular tool for policy making in modern democracies. Although there are advantages of bringing policymaking closer to the people, one important concern is that the trend toward direct democracy might threaten the interests of minorities who are vulnerable to the tyranny of the majority. Political scientists are just beginning to rigorously grapple with this important issue. In this study, we address the lack of causal evidence through a natural experiment that exploits exogenous institutional change from direct to representative democracy. We find that immigrant minorities in Switzerland fare much better if their naturalization applications are decided by politicians in legislatures rather than by citizens in naturalization referendums. Further evidence suggests an important channel through which this effect operates is the heightened legal

\footnotetext{
${ }^{2}$ If politicians vote more liberally solely to avoid the hassle of an appeal, we would expect the relative number of any appeal, successful or unsuccessful, to increase the naturalization rate in the following year. However, we do not find any effect for the relative number of unsuccessful appeals across all specifications. Only successful appeals are correlated with politicians' future naturalization decisions.
}

accountability that politicians face compared to citizens when deciding on the naturalization requests.

Our findings have several important implications. With respect to the Swiss context, the results demonstrate that direct democracy acts as a significant barrier to citizenship. The fact that naturalization rates increase sharply with the transition from direct to representative democracy, while the quality of the applicant pool remains constant, suggests that voters in naturalization referendums discriminate against a significant proportion of qualified applicants who would be approved if accountable legislators, who have to publicly justify their decisions and are subject to judicial oversight, were to vote on the same applications. This evidence suggests that direct democracy should no longer be used for naturalization decisions if the goal is to lower the risk of discriminatory rejections. This is a pressing concern given recent proposals to constitutionally restore secret ballot referendums for naturalizations and the fact that by the end of our sample period, some municipalities still continue to rely on referendums to decide on naturalization applications at the citizens assembly.

More broadly, our results emphasize the importance of the interplay between voter preferences and political institutions in generating policy outcomes. Our study provides perhaps the most direct evidence to date that when faced with the exact same policy decision, direct democracy does harm minorities more often than representative democracy. Moreover, the evidence suggests that direct democracy is most harmful for the most marginalized minorities. This finding has direct implications for the long-standing literature on the effect of direct democracy on minority interests. It supports the warnings by opponents of direct democracy and contradicts the claims of its supporters who argue that there exists no rigorous evidence that direct democracy harms minority interests. Finally, from a theoretical perspective, we have identified a novel mechanism that explains how institutional constraints can limit discretion and thereby mitigate how prejudices translate into policy. In particular, our results suggest that shifting authority to a venue in which decision makers are accountable to report on the reasons for their decisions is beneficial for minorities who are at risk of discrimination.

How generalizable are our findings? Although it would be unwise to conclude from our results that direct democracy is generally harmful for minorities, our results show that at least in the important domain of naturalizations, where the causal effect of direct democracy can be isolated empirically, minorities suffer from direct democracy when faced with an antagonistic electorate. Whether direct democracy would be more 
or less harmful in other contexts is more difficult to assess. We need to consider two questions about the external validity. First, is Switzerland different? Second, are naturalization referendums different?

If direct democracy amplifies the preferences of the majority, then one possibility is that the negative effects of direct democracy that we find are more pronounced in Switzerland because the Swiss are more anti-immigrant than natives in most other places. However, the evidence contradicts the idea that the Swiss are unusually xenophobic. In fact, cross-national data on immigration attitudes from the European Social Survey and World Values Survey suggest that across a broad range of measures, Switzerland consistently ranks among the countries with the lowest levels of anti-immigrant sentiment (see the SI for details). This supports the conjecture that, if anything, we might expect even more harmful effects if other countries were to allow voters to express their preferences on immigrants in referendums.

Another possibility is that the effects of direct democracy differ in our setting because naturalization votes are a special case. In particular, one distinguishing feature is that naturalization referendums entail votes on individual immigrants, rather than votes on broader policies that affect the minority group as a whole. But would direct democracy be more or less harmful if voters decided on minority groups, rather than the individuals who belong to these groups? The large social psychology literature on the "person-positivity bias" (Sears 1983) supports the conjecture that direct democracy would most likely be more harmful if decisions applied to entire minority groups. It is a central finding that individuals are regularly viewed more positively than the groups or categories they embody and that individuating information can act to override stereotypes and encourage perceivers to form judgments on the merits of the individual (LaPiere 1934; Sears 1983). This person-positivity bias has been replicated in different domains, including the area of immigration in which Iyengar et al. (2013) show that voters fiercely oppose open immigration policies, even though they are generally much more welcoming toward individual immigrants. We expect that a similar person-positivity bias is also at play in our naturalization setting, where votes are cast based on lots of individuating information about the applicants.

In sum, both lines of reasoning about external validity suggest that our results likely provide a lower bound for the harmful effects of direct democracy on immigrant minorities. Nonetheless, it is our view that external validity is best addressed not by theoretical conjectures, but by replicating internally valid studies in other countries and in other policy domains.

\section{References}

Acemoglu, Daron. 2005. "Constitutions, Politics, and Economics: A Review Essay on Persson and Tabellini's 'The Economic Effects of Constitutions." Journal of Economic Literature 43(4): 1025-48.

Cronin, Thomas E. 1989. Direct Democracy: The Politics of Initiative, Referendum, and Recall. Cambridge, MA: Harvard University Press.

Donovan, Todd, and Shaun Bowler. 1998. "Direct Democracy and Minority Rights: An Extension." American Journal of Political Science 42(4): 1020-24.

Downs, Anthony. 1957. An Economic Theory of Democracy. 1st ed. Harper and Row.

Frey, Bruno S., and Lorenz Goette. 1998. "Does the Popular Vote Destroy Civil Rights?” American Journal of Political Science 42(4): 1343-48.

Gamble, Barbara S. 1997. "Putting Civil Rights to a Popular Vote.” American Journal of Political Science 41(1): 245-69.

Gerber, E., and S. Hug. 2001. "Minority Rights and Direct Legislation: Theory, Method and Evidence." In Referendum Democracy: Citizens, Elites, and Deliberation in Referendum Campaigns, ed. Mendelsohn, M. and Parkin, A. New York: Palgrave Macmillan UK.

Haider-Markel, Donald P., Alana Querze, and Kara Lindaman. 2007. "Lose, Win, or Draw? A Reexamination of Direct Democracy and Minority Rights." Political Research Quarterly 60(2): 304-14.

Hainmueller, Jens, and Dominik Hangartner. 2013. "Who Gets a Swiss Passport? A Natural Experiment in Immigrant Discrimination." American Political Science Review 107(1): 15987.

Hainmueller, Jens, Dominik Hangartner, and Giuseppe Pietrantuono. 2015. "Naturalization Fosters the Long-Term Political Integration of Immigrants.” Proceedings of the $\mathrm{Na}$ tional Academy of Sciences 112(41): 12651-56.

Hainmueller, Jens, Dominik Hangartner, and Giuseppe Pietrantuono. 2017. "Catalyst or Crown: Does Naturalization Promote the Long-Term Social Integration of Immigrants?" American Political Science Review 111(2): 256-76.

Hajnal, Zoltan L. 2009. "Who Loses in American Democracy? A Count of Votes Demonstrates the Limited Representation of African Americans." American Political Science Review 103(1): 37-57.

Hajnal, Zoltan L., E. R. Gerber, and H. Louch. 2002. "Minorities and Direct Legislation: Evidence from California Ballot Proposition Elections." Journal of Politics 64(1): 154-77.

Helbling, M., and H. Kriesi. 2004. "Staatsbürgerverständnis und politische Mobilisierung: Einbürgerungen in Schweizer Gemeinden.” Swiss Political Science Review 10(4): 33-58.

Hug, S. 2003. Voices of Europe: Citizens, Referendums, and European Integration. Lanham, MD: Rowman \& Littlefield.

Iyengar, Shanto, Simon Jackman, Solomon Messing, Nicholas Valentino, Toril Aalberg, Raymond Duch, Kyu S. Hahn, Stuart Soroka, Allison Harell, and Tetsuro Kobayashi. 2013. "Do Attitudes about Immigration Predict Willingness to Admit Individual Immigrants? A Cross-National Test of the Person-Positivity Bias." Public Opinion Quarterly 77(3): 641-65. 
Kriesi, H., R. Lachat, P. Selb, S. Bornschier, and M. Helbling. 2005. Der Aufstieg der SVP. Acht Kantone im Vergleich. Zürich: NZZ-Verlag.

LaPiere, Richard T. 1934. "Attitudes vs. Actions." Social Forces 13(2): 230-37.

Lee, Woojin, John Roemer, and Karine Straeten. 2006. "Racism, Xenophobia, and Redistribution." Journal of the European Economic Association 4(2-3): 446-54.

Madison, James. 1961. "The Same Subject Continued: The Union as a Safeguard Against Domestic Faction and Insurrection." In The Federalist, ed. Hamilton Alexander, John Jay, and James Madison. Cambridge, MA: Belknap Press of Harvard University Press, 45-51.

Matsusaka, J. G. 2005. “Direct Democracy Works.” Journal of Economic Perspectives 19(2): 185-206.

Moore, R. T., and N. Ravishankar. 2012. "Who Loses in Direct Democracy?" Social Science Research 41(3): 646-56.

OECD, ed. 2011. Naturalisation: A Passport for the Better Integration of Immigrants? Paris: OECD Publishing.

Olken, B. A. 2010. "Direct Democracy and Local Public Goods: Evidence from a Field Experiment in Indonesia." American Political Science Review 104(2): 243-67.

Preuhs, Robert R. 2005. "Descriptive Representation, Legislative Leadership, and Direct Democracy: Latino Influence on English Only Laws in the States, 1984-2002." State Politics \& Policy Quarterly 5(3): 203-24.

Przeworski, Adam. 2007. "Is the Science of Comparative Politics Possible?" In Oxford Handbook of Comparative Politics, ed. Carles Boix and Susan C. Stokes. New
York: Oxford University Press, https://doi.org/10.1093/ oxfordhb/9780199566020.003.000.

Schildkraut, Deborah J. 2001. "Official-English and the States: Influences on Declaring English the Official Language in the United States." Political Research Quarterly 54(2): 445-57.

Sears, David O. 1983. "The Person-Positivity Bias." Journal of Personality and Social Psychology 44(2): 233-50.

Tolbert, C. J., and D. A. Smith. 2006. "Representation and Direct Democracy in the United States." Representation: Journal of Representative Democracy 42(1): 25-44.

Vatter, Adrian, and Deniz Danaci. 2010. "Mehrheitstyrannei durch Volksentscheide?" Politische Vierteljahresschrift 51: 205-22.

Zimmerman, Joseph F., and J. Francis. 1986. Participatory Democracy: Populism Revived. New York: Praeger.

\section{Supporting Information}

Additional supporting information may be found online in the Supporting Information section at the end of the article.

Appendix A: Data Sources

Appendix B: Additional Results

Appendix C: Additional Detail on Court Rulings

Appendix D: External Validity 